\title{
Correction to: A Robotic Augmented Reality Virtual Window for Law Enforcement Operations
}

\author{
Nate Phillips, Brady Kruse, Farzana Alam Khan, J. Edward Swan II, \\ and Cindy L. Bethel
}

\author{
Correction to: \\ Chapter "A Robotic Augmented Reality Virtual Window \\ for Law Enforcement Operations" \\ in: J. Y. C. Chen and G. Fragomeni (Eds.): Virtual, Augmented \\ and Mixed Reality, LNCS 12190, \\ https://doi.org/10.1007/978-3-030-49695-1_40
}

The original version of this chapter was revised. The acknowledgement was inadvertently forgotten. It has been added. 